\title{
Jugendwohlfahrt und Erwachsene
}

\author{
Ein Mahnwort an die Erwachsenen
}

Man kann nicht auf die Jugend blicken, ohne an die Erwachsenen zu denken. Jugendwohlfahrt ist nicht zu trennen von der Mitwirkung und Verantwortung der Erwachsenen.

Jugend reift von Kindheit zu Mannestum und Frauenhaftigkeit; Jugend wird erwachsen. Es ist eine Entwicklungslinie vorhanden, die von der Jugend zu den Erwachsenen führt. Jugend und Erwachsene sind in Gemeinschaften miteinander verbunden, in Familie und Volk.

Verwahrloste Jugend ist nicht gleichgültig für ein Volk. Die Jugend der Gegenwart ist das Volk der Zukunft. Ist Jugend verwahrlost und wird sie nicht geheilt, so wird ein kranker Volkskörper. Ein Volk kann an seiner verwahrlosten Jugend zugrunde gehen. Verwahrloste Jugend kann Untergang des Volkes bedeuten. Dessen müssen sich die Erwachsenen bewußt sein, wenn sie auf ihre Jugend schauen. „Das Erziehungssystem eines Volkes ist viel wichtiger als sein Regierungssystem", heißt ein Wort Eliots.

Jugendverwahrlosung ist eine ernste Krise für ein Volk. Das Jugendproblem ist bei uns und bei anderen Völkern mehr noch als nach dem ersten Weltkriege zum Problem der Gegenwart geworden, das gemeistert werden muß neben all den Wirtschaftsfragen.

Hauptursache der Jugendnot ist die Schuld der Erwachsenen. Überwindung und Heilung der Jugendnot ist nur möglich bei Verantwortung der Erwachsenen. Schuld muß Verantwortung auslösen. Wo sie es nicht tut, wird Verantwortungslosigkeit zu neuer Schuld, die sich zu der alten häuft. So verstanden - Schuld und Verantwortung jedes einzelnen Erwachsenen im tiefsten Sinne des Wortes - wird uns der Ernst der Lage bewußt. Es kann gar nicht oft genug betont und gar nicht oft genug gesagt werden:

Erwachsene, denkt an euere Jugend! Es ist euere Jugend. Was ihr aus dieser Jugend macht oder was ihr aus ihr werden laßt, wird diese Jugend letzten Endes. Der entscheidende Einfluß ist in euerer Hand trotz all der vielen anderen Ursachen. Die Notstände mögen stark sein, sie mögen unüberwindlich erscheinen. Kann der Mensch die Not nicht bezwingen, so kann er doch seinem Mitmenschen helfen. Das gebieten Menschlichkeit und Nächstenliebe. Die Not in all ihrer Vielgestaltigkeit äußerer und innerer Art ist eine traurige Erscheinung der Umwelt. Die Not ist für den einzelnen, wie für ein Volk das, was der Mensch in seinem Inneren aus ihr macht, wie er sich zu ihr stellt. Wir erleben es immer 
wieder: eine jugendliche Seele, die in Notzeiten richtig geleitet wird, kann reifen und erstarken.

Es ist bezeichnend, da $\beta$ Bader in seinem bedeutungsvollen Buch "Soziologie der deutschen Nachkriegskriminalität", in dem allen Ursachen genau nachgegangen wird, auf der letzten Seite schreibt: „Nicht die Anstalten sind es, die unserer Jugend helfen können, sondern wir selbst: die Erwachsenen." Er weist hierbei auf einen Satz der amtlichen Denkschrift über das Borstal-System hin, der lautet: ,Es sind Männer und nicht Gebäude, die die Herzen irregeführter Jugend ändern." 